upon the digestive or assimilating powers of the stomach, apply with augmented force when disease, or even a predisposition to a prevailing complaint, is present. Now a little imagination may render the simplest article of food indigestible, or make it actually noxious. Every one knows, that suspicion or fear has an instant effect on the stomach; and when this suspicion is directed to the stomach itself, its influence is augmented in a geometrical ratio. The digestive organs for a time are paralyzed, and the food is no longer subject tn animal laws, Lut is changed upon chemical principles. 'The effects of medicine, in like manner, are essentially counteracted, or materially assisted, according to the state of the mind, and its direction to the stomach, and the supposed good or ill action of the remedy.

On the whole, after a pretty attentive consideration of the subject, I am strongly inclined to believe that the popular treatises upon diet and regimen, the habitual lecturing of students upon their health, and the newspaper recommendations and proscriptions of food and drink, have been the cause of ten cases of dyspepsia, in the place of one which they have prevented or removed. It is said that no susceptible person can fix his attention upon his heart, for five minutes at a time, witlsout producing pain or distress, or varying the action of that vital organ. The same is probably the fact with the stomach, and peculiarly so when an epidemic is prevailing, which has one of its prominent seats in the organs of digestion. A regular habit of using the bounties of Providence with temperance and moderation, is about all that can ever be enforced upon the public to advantage. All popular directions, besides the rules of common sense and common prudence, are liable to be misunderstood and perverted, and be carried to extremes which inake them worse than useless-increasing the very evils which they were benevolently, but injudiciously, designed to diminish.

Amicus.

\title{
A CASE not Reported as cholera.
}

$$
\text { BY E. G. DAVIS, M.D. }
$$

[Communicated for the Boston Medical and Surgical Journal.]

ON Friday, September Yth, at seven o'clock, P. M., I visited, with my friend Dr. J. J., a married woman, S. S., about twenty years of age, living in a narrow alley leading out of Essex Street. I understood that she was very near her period of confinement ; that she had had dysentery twice during the last week, which had been controlled by treatment; and that in consequence of gross imprudence in diet the evening previous, she had been attacked with vomiting and purging in the night. We found her lying in a filthy bed, and half covered with dirty, wee clothing; her countenance rather sunken, indicating some distress; her skin universally moist, the face being bedewed with perspiration; her trunk cool, and extremities cold; the arms and legs nearly as much so as in death; her breath cool; her tongue becoming so almost immediately on being protruded-dry, not coated. Her pulse was about 150 , and very small. Her thirst was excessive, and her calls for water peculiarly urgent. She 
complained of no pain, but had a burning sensation at epigastrium. She had had no vorniting or purging, by report, for some hours. Spasms were almost constantly present during the whole of the visit, which lasted an hour. They affected principally the muscles of the calves, the flexors of the toes and those of the fingers. The fore fingers were repeatedly drawn asunder from the rest in a lateral direction. She did not appear to suffer from the cramp, but begged continually to have her extremities rubbed. Her voice was not affected, and her mind continued unimpaired. She lay for some minutes at a time quite still, as if asleep. Her fingers, when unaffected by spasm, were semi-flexed, furrowed with longitudinal wrinkles, and having much the appearance as if they had been soaked in warm water for three or four hours. The state of the bed produced a suspicion that the liquor amnii had been discharged. On examination, this was ascertained not to be the fact : the os uteri was found somewhat dilated, and the head of the fœtus was perceived through the membranes. She became worse during the visit, although much exertion was made to produce external heat, and to restore the circulation.

At nine o'clock, seen again. The skin of the face, chest, and extremities, are bathed in sweat, with large drops exuding from every pore, and deathly cold. The countenance is ghastly, and intensely anxious. The respiration is laborious, sometimes gasping. The alæ nasi are expanded in breathing; the eyes are surrounded with a livid areola; the voice has become a little husky; the mind continues clear; the heat in stomach has left her; the spasms have nearly ceased. No vomiting or purging. Just before ten o'clock she became more restless ; lifted herself in bed; threw about her arms; said she was dying; threw her head over the bed; vomited without effort twice or three times; then fell back and expired.

Examination of the body was not permitted.

Boston, September, 1832.

\section{HAMOPTYSIS.}

A Case of Hamoplysis. By H. A. Barrows, M.D., Leeds, Maine.

[Communicated for the Boston Medical and Surgical Journal.]

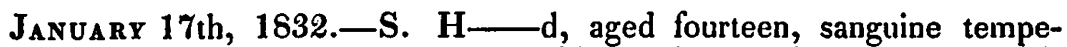
rament, light hair and eyes, with a fair, delicate skin, and other indications of scrofulous habit; predisposed to pulmonary affections by hereditary constitution; is one of twelve children, of whom half are now dead, and all but one of tubercular phthisis. All died young, but not so young as the present subject.

This patient has suffered hemorrhage from the lungs for ten weeks, generally in moderate quantities two or three times each week; has a slight cough, and a little uneasiness in the right lung; expression of countenance lively and quite natural, though somewhat emaciated; pulse quick and sharp, but never full or hard ; breathing quite natural ; appetite tolerable, digestion good, and rests tolerably well. 